\title{
Diagnostic and prognostic values of integrin $\alpha$ subfamily mRNA expression in colon adenocarcinoma
}

\author{
YI-ZHEN GONG $^{1 *}$, GUO-TIAN RUAN ${ }^{1 *}$, XI-WEN LIAO ${ }^{2}$, XIANG-KUN WANG ${ }^{2}$, \\ CUN LIAO $^{1}$, SHUAI WANG ${ }^{1}$ and FENG GAO ${ }^{1}$ \\ Departments of ${ }^{1}$ Colorectal and Anal Surgery and ${ }^{2}$ Hepatobiliary Surgery, The First Affiliated Hospital of \\ Guangxi Medical University, Nanning, Guangxi Zhuang Autonomous Region 530021, P.R. China
}

Received February 14, 2019; Accepted June 26, 2019

DOI: 10.3892/or.2019.7216

\begin{abstract}
The integrin $\alpha(I T G A)$ subfamily genes play a fundamental role in various cancers. However, the potential mechanism and application values of ITGA genes in colon adenocarcinoma (COAD) remain elusive. The present study investigated the significance of the expression of ITGA genes in COAD from the perspective of diagnosis and prognosis. A COAD RNA-sequencing dataset was obtained from The Cancer Genome Atlas. The present study investigated the biological function of the ITGA subfamily genes through bioinformatics analysis. Reverse transcription-quantitative polymerase chain reaction was applied to investigate the distribution of integrin $\alpha 8$ (ITGA8) expression in COAD tumors and adjacent normal tissues. Bioinformatics analysis indicated that ITGA genes were noticeably enriched in cell adhesion and the integrin-mediated signaling pathway, and co-expressed with each other. It was also revealed through observation that the majority of gene expression was significantly low in tumor tissues $(\mathrm{P}<0.05)$, and diagnostic receiver operating characteristic curves revealed that most of the genes could serve as significant diagnostic markers in COAD $(\mathrm{P}<0.05)$, especially ITGA8 which had a high diagnostic value with an area under curve (AUC) of 0.989 [95\% confidence interval (CI) 0.980-0.997] in COAD ( $\mathrm{P}<0.0001)$. In addition, ITGA 8 expression was verified in clinical samples and it was revealed that it was higher in adjacent normal tissues $(\mathrm{P}=0.041)$ compared to COAD tissues, and the AUC was 0.704 (95\% CI, 0.577-0.831; $\mathrm{P}<0.0085)$. Multivariate survival analysis indicated that integrin $\alpha$ (ITGA5) may be an independent
\end{abstract}

Correspondence to: Professor Feng Gao, Department of Colorectal and Anal Surgery, The First Affiliated Hospital of Guangxi Medical University, 6 ShuangYong Road, Nanning, Guangxi Zhuang Autonomous Region 530021, P.R. China

E-mail: doctor0771@163.com

*Contributed equally

Key words: integrin $\alpha$, mRNA, colon adenocarcinoma, prognosis, diagnosis prognostic indicator for COAD overall survival. Gene set enrichment analysis indicated that ITGA5 may participate in multiple biological processes and pathways. The present study revealed that ITGA genes were associated with the diagnosis and prognosis of COAD. The mRNA expression of ITGA8 may be a potential diagnosis biomarker and ITGA5 may serve as an independent prognosis indicator for COAD.

\section{Introduction}

Colon cancer (CRC) is the fourth leading cause of cancer-related deaths throughout the world after lung, breast, and prostate cancer. Based on the GLOBOCAN data, more than 1.8 million newly diagnosed carcinoma cases and 881,000 deaths related to this disease occurred in 2018 worldwide (1). Colon adenocarcinoma (COAD) is one of the most common pathological types of colon cancer (2). In recent years, colon adenocarcinoma has a significant upward trend in morbidity and mortality (3), especially in Western developed countries and Asian developing countries (4). Although, there are many treatments, including surgery and chemotherapy, the five-year survival rate of COAD is still not promising (5). Late diagnosis, unreliable biomarkers and therapeutic targets have become major obstacles in the treatment of colon adenocarcinoma (6). Therefore, early diagnosis and treatment are essential for the improvement of the prognosis and quality of life of the patients. Finding new targets in COAD may provide new alternatives and insights for comprehensive management strategies for COAD patients.

Integrins belong to heterodimeric surface receptors, which are composed of non-covalently associated $\alpha$ and $\beta$ subunits, and as far as we know, the integrin family consists of $18 \alpha$ and $8 \beta$ members (7-11). ITGA, a subfamily of integrins, has an $\alpha$ subunit composed of a seven-bladed $\beta$-propeller, a thigh, and two calf domains (12). There is an I domain (also called A domain), composed of 200 amino acids inserted between blades 2 and 3 in the $\beta$-propeller, and contained in nine of the 18 integrin $\alpha$ chains (13). There are also domains that bind $\mathrm{Ca}^{2+}$ on the lower side of the blades facing away from the ligand-binding surface which are contained in the last three or four blades of the $\beta$ propeller. Ligand binding is influenced by $\mathrm{Ca}^{2+}$ binding to these sites allosterically $(14,15)$. Previous research has revealed that the integrin family mediates signal transduction by binding to the extracellular matrix 
via adhesion receptors on its surface (16). Each integrin has multiple activation states (12), and exerts effects through cascaded amplification of various paths (17). Extensive studies have revealed that integrins could function as signaling molecules through the cell membrane in either direction: 'inside-out signaling' caused by extracellular stimulation that causes intracellular linin and kindlin to bind to the cytoskeleton, leaving the extracellular domain in a high affinity state $(8,18-20)$; and 'outside-in signaling', a complicated process in which the heterodimeric adhesion receptors of the integrins mediate cell adhesion to the extracellular matrix (ECM), then activate integrins to engage and interact with the cytoskeleton in order to activate a variety of intracellular signaling pathways (12), which enhance binding of activated integrin ligands and allow for the perception of the intracellular environment $(9,20,21)$. These integrins could control cell attachment, movement, growth and differentiation, as well as survival $(12,22)$.

Integrins modulate muititudinal human pathologies including thrombotic diseases, infectious diseases, inflammation, fibrosis, and cancer (17). In cancer, members of the integrin family of pattern recognition receptors participate in many cellular processes in the body, including adhesion, metastatic spread of tumor cells, and identification (22). In addition to altering the interaction of cells with the surrounding environment, the proliferation, survival and differentiation of cancer cells can be promoted by integrins through growth factors such as EGFR, VEGFR interaction, or tyrosine kinase receptors (23). Integrins, as cell adhesion receptors, are also observed and have been reported in various types of cancer, such as multiple myeloma (24), NSCLC (25), glioma (26), ovarian cancer (27) and oral squamous cell carcinoma (28). However, the potential mechanism and application value of ITGA genes remain elusive. Therefore, the aim of the present study was to explore the potential application of ITGA genes of COAD in the perspective of diagnosis and prognosis by using an RNA-sequencing (RNA-Seq) dataset from The Cancer Genome Atlas (TCGA; https://tcga-data.nci.nih.gov/).

\section{Materials and methods}

Patient information. TCGA databases were accessed on October 30, 2018, and a total of 456 COAD patient clinical parameters which consisted of 480 tumor and 41 adjacent normal tissue samples were collected. Clinical parameter information including sex, age, survival time (days), survival status and tumor-node-metastasis (TNM) stage were obtained.

Bioinformatics analysis of ITGA genes. To study the biological enrichment function of the ITGA subfamily, the online tool Database for Annotation, Visualization, and Integrated Discovery (DAVID) (https://david.ncifcrf.gov/; version 6.8; accessed January 5, 2019) (29,30), containing gene ontology (GO) enrichment functional analysis and Kyoto Encyclopedia of Genes and Genomes (KEGG) pathway analysis $(31,32)$ was used. An enrichment P-value $<0.05$ was considered as significant from a statistical perspective. Gene ontology includes 3 independent modules, biological processes (BP), molecular functions (MF), and cellular components (CC) (31). GO terms of ITGA genes were also obtained using the Biological Networks Gene Ontology tool (BiNGO) in Cytoscape_version 3.6.1 (33). Gene-gene interactions of ITGA genes were then investigated using Gene Multiple Association Network Integration Algorithm (GeneMANIA, http://www.genemania.org/, accessed December 25, 2018) (34). Protein-protein interactions (PPI) of ITGA genes were performed using the Search Tool for the Retrieval of Interacting Genes (STRING; https://string-db.org/, accessed November 19, 2018) $(35,36)$.

$m R N A$ expression levels of ITGA genes and diagnostic receiver operating characteristic (ROC) curves. The mRNA expression levels of ITGA genes were presented by box plots and scatter plots. A box plot of ITGA genes was downloaded from the Metabolic gEne RApid Visualizer (MEARV) (http://merav. wi.mit.edu/, accessed January 21, 2019) (37), while a scatter plot was generated from the TCGA dataset to integrate cancer and adjacent normal tissues of mRNA expression levels at $75 \%$ cut-off values. Diagnostic ROC curves investigated the statistically significant expression of tumor tissues and adjacent normal tissues in TCGA cohort.

Verification of the first affiliated hospital of Guangxi medical university cohort

COAD patient tissue samples. COAD patient tissues, 30 in all, including tumor tissues and paired adjacent normal tissues, were collected (from April to June 2018) at the Department of Colorectal and Anal Surgery of The First Affiliated Hospital of Guangxi Medical University (Nanning, China). All patients signed an informed consent form, and the experimental protocol was approved by the Ethics Committee of the First Affiliated Hospital of Guangxi Medical University. [No. 2019(KY-E-001)]. Immediately after surgery, the tissue was placed in RNA protection solution and transferred to a $-80^{\circ} \mathrm{C}$ refrigerator for preservation. The postoperative pathological diagnosis was COAD.

Detection of ITGA8 expression by reverse transcriptionquantitative polymerase chain reaction $(R T-q P C R)$. RT-qPCR was performed to assess ITGA8 expression in COAD tissue samples, including tumor and adjacent normal tissues. TRIzol ${ }^{\circledR}$ reagent (15596026; Invitrogen; Thermo Fisher Scientific, Inc.) was used to extract total RNA from tissues. Total RNA concentration was detected by NanoDrop One (Thermo Fisher Scientific, Inc.). And the RNA was reverse-transcribed (20- $\mu 1$ reaction system) applying a reverse transcription kit (Applied Biosystems; Thermo Fisher Scientific, Inc.) to create cDNA. Then in accordance with the FastStart Universal SYBR Green Master (ROX) kit (Roche Diagnostics) and the Applied Biosystems Quantsudio $^{\text {TM }}$ Real-Time PCR System (Q6) operation guide (Applied Biosystems; Thermo Fisher Scientific, Inc.), the reaction procedure was set up. The reaction conditions used were as follows: Pre-denaturation at $95^{\circ} \mathrm{C}$ for $10 \mathrm{~min}$; then denaturation at $95^{\circ} \mathrm{C}$ for $15 \mathrm{sec}, 60^{\circ} \mathrm{C}$ extension for $60 \mathrm{sec}, 40$ cycles; finally denaturation at $95^{\circ} \mathrm{C}$ for $15 \mathrm{sec}, 60^{\circ} \mathrm{C}$ for $1 \mathrm{~min}, 95^{\circ} \mathrm{C}$ for $30 \mathrm{sec}$, and $60^{\circ} \mathrm{C}$ for $15 \mathrm{sec}$. GAPDH was used as an internal reference gene, and the primer sequences of ITGA 8 and GAPDH were synthesized by Sangon Biotech Co., Ltd. The primer sequences were as follows: GAPDH forward, 5'-TGGTCCCTGCTCCTCTAAC-3' and reverse, 5'-GGCTCA ATGGCGTACTCTC-3'; and ITGA8 forward, 5'-GCTGCT 
Table I. Baseline patient characteristics in a TCGA cohort.

OS

\begin{tabular}{|c|c|c|c|c|c|}
\hline \multirow[b]{2}{*}{ Variables } & \multirow[b]{2}{*}{ Patients $(n=438)$} & \multicolumn{4}{|c|}{ OS } \\
\hline & & No. of events & MST (months) & $\mathrm{HR}(95 \% \mathrm{CI})$ & Log-rank P-value \\
\hline \multicolumn{6}{|c|}{ Age (years) } \\
\hline$<65$ & 168 & 30 & NA & 1 & 0.17 \\
\hline$\geq 65$ & 268 & 67 & 82.5 & $1.353(0.879-2.081)$ & \\
\hline Missing $^{\mathrm{a}}$ & 2 & & & & \\
\hline \multicolumn{6}{|l|}{ Sex } \\
\hline Male & 234 & 54 & 82.5 & 1 & 0.545 \\
\hline Female & 204 & 44 & NA & $0.884(0.593-1.318)$ & \\
\hline \multicolumn{6}{|l|}{ Stage } \\
\hline 1 and 2 & 240 & 34 & 101.4 & 1 & $<0.001$ \\
\hline 3 and 4 & 187 & 59 & 62.7 & $2.684(1.758-4.099)$ & \\
\hline Missing $^{\mathrm{b}}$ & 11 & & & & \\
\hline
\end{tabular}

${ }^{a}$ Missing, information of age was unknown in 2 patients; ${ }^{b}$ Missing, information of TNM stage was not reported in 10 patients. TCGA, The Cancer Genome Atlas; OS, overall survival; MST, median survival time; 95\% CI, 95\% confidence interval; HR, hazards ratio; NA, not available.

GGGGAGTTTACTGG-3' and reverse, 5'-GATGCCATCTGT TCTCCCGTG-3'. The gene expression level in the present study was calculated using the $2^{-\Delta \Delta C q}$ method (38).

Survival analysis. In TCGA database, 438 COAD patients were categorized into two groups namely a high and low-expression group, which were based on the $75 \%$ cut-off value of gene expression. Kaplan-Meier survival analysis was performed for sex, age, and stage, respectively. Then overall survival (OS) was determined to evaluate the prognostic value of COAD patients. Furthermore, sex, age, and TNM stage were adjusted using Cox proportional hazards regression model in TCGA database.

Gene set enrichment analysis (GSEA). To further explore the potential value of biological processes and pathways, multivariate prognostic significance of the ITGA5 gene was grouped into low and high expression categories based on the $75 \%$ cut-off value of the expression levels. GSEA (http://software.broadinstitute.org/gsea/ index.jsp, downloaded January 20, 2018) $(39,40)$ was conducted to investigate underlying mechanisms by using the Molecular Signatures Database (MSigDB) c2 (c2.cp.kegg. v6.2.symbols.gmt) and c5 (c5.all.v6.2.symbols.gmt) (41). The enrichment gene sets in GSEA were identified as statistically significant when a nominal P-value $<0.05$ and a false discovery rate $(\mathrm{FDR})<0.25$ were attained.

Statistical analysis. Kaplan-Meier survival analysis and the log-rank test were conducted to assess different subgroups categorized by clinical and gene variables. Adjusted hazard ratios (HRs) and 95\% confidence intervals (CIs) were obtained using univariate and multivariate Cox proportional hazards models. TNM stage was selected to set up a Cox proportional hazard regression model. The paired t-test was applied for comparison of data between COAD tumors and adjacent normal tissues. A P $<0.05$ indicated that the differences exhibited statistical significance. The FDR in GSEA was adjusted for multiple testing according to the Benjamini-Hochberg procedure $(42,43)$. All of the aforementioned statistical analyses were performed with SPSS Statistics software version 20.0 (IBM Corp.). Vertical scatter plots, ROC and survival curves were plotted using GraphPad Prism v.7.0 (GraphPad Software, Inc.).

\section{Results}

Baseline patient characteristics in TCGA. The expression of the ITGA subfamily of related genes was included from the TCGA RNAseq database. Firstly, information concerning tumor and adjacent normal tissues was isolated. Then clinical information was integrated with gene expression. In addition, cases that had no clinical prognostic information and people who had a survival time of 0 were excluded. Finally, information on the $438 \mathrm{COAD}$ patient tumor samples and 41 adjacent normal tissue samples was obtained. Detailed baseline characteristics of the 438 COAD patients from the TCGA database are summarized in Table I. It was revealed that sex and age were not correlated with OS (all $\mathrm{P}>0.05$ ). However, TNM stage was notably associated with OS (log-rank test $\mathrm{P}<0.001$, adjusted $\mathrm{P}<0.001$ ).

Analysis of ITGA subfamily mRNA expression levels in TCGA databases. The $75 \%$ cut-off value of gene expression levels was used to categorize COAD patients into low-level groups and high-level groups. Then TNM stage was used for adjustment of these genes. Multivariate analysis indicated that ITGA5 exhibited statistical significance $[\mathrm{P}=0.016 ; \mathrm{HR}(95 \% \mathrm{CI})=1.681$ (1.100-2.570)] (Table II).

Bioinformatics analysis of the ITGA genes. GO term enrichment analysis of ITGA genes revealed that biological processes mainly involved cell adhesion and the integrin-mediated signaling pathway (Fig. 1A and S1). KEGG pathway analysis mainly involved focal adhesion, the PI3K/AKt signaling 
Table II. Prognostic values of ITGA subfamily gene expression in COAD of a TCGA cohort.

\begin{tabular}{|c|c|c|c|c|c|}
\hline \multirow[b]{2}{*}{ Gene } & \multirow[b]{2}{*}{ Patients $(n=438)$} & \multicolumn{4}{|c|}{ OS } \\
\hline & & No. of events & MST (days) & $\mathrm{HR}(95 \% \mathrm{CI})$ & Adjusted P-value ${ }^{a}$ \\
\hline \multicolumn{6}{|l|}{ ITGAI } \\
\hline Low & 329 & 77 & 3,042 & 1 & 0.303 \\
\hline High & 109 & 21 & 2,134 & $0.775(0.477-1.259)$ & \\
\hline \multicolumn{6}{|l|}{ ITGA2 } \\
\hline Low & 329 & 78 & 2,532 & 1 & 0.176 \\
\hline High & 109 & 20 & NA & $0.711(0.434-1.165)$ & \\
\hline \multicolumn{6}{|c|}{ ITGA2B } \\
\hline Low & 329 & 74 & 2,475 & 1 & 0.792 \\
\hline High & 109 & 24 & NA & $1.064(0.670-1.691)$ & \\
\hline \multicolumn{6}{|l|}{ ITGA3 } \\
\hline Low & 329 & 70 & 2,532 & 1 & 0.898 \\
\hline High & 109 & 28 & 2,047 & $0.971(0.620-1.521)$ & \\
\hline \multicolumn{6}{|l|}{ ITGA4 } \\
\hline Low & 329 & 73 & 2,821 & 1 & 0.434 \\
\hline High & 109 & 25 & 1,661 & $1.203(0.757-1.912)$ & \\
\hline \multicolumn{6}{|l|}{ ITGA5 } \\
\hline Low & 329 & 73 & 2,821 & 1 & 0.016 \\
\hline High & 109 & 25 & 2,047 & $1.681(1.100-2.570)$ & \\
\hline \multicolumn{6}{|l|}{ ITGA6 } \\
\hline Low & 329 & 77 & 2,532 & 1 & 0.284 \\
\hline High & 109 & 21 & NA & $0.767(0.471-1.246)$ & \\
\hline \multicolumn{6}{|l|}{ ITGA7 } \\
\hline Low & 329 & 73 & 2,532 & 1 & 0.763 \\
\hline High & 109 & 25 & 3,042 & $0.932(0.59-1.472)$ & \\
\hline \multicolumn{6}{|l|}{ ITGA 8} \\
\hline Low & 329 & 80 & 2,475 & 1 & 0.206 \\
\hline High & 109 & 18 & NA & $0.718(0.430-1.199)$ & \\
\hline \multicolumn{6}{|l|}{ ITGA9 } \\
\hline Low & 329 & 62 & 2,821 & 1 & 0.165 \\
\hline High & 109 & 36 & 2,047 & $1.340(0.887-2.024)$ & \\
\hline \multicolumn{6}{|c|}{ ITGA10 } \\
\hline Low & 329 & 69 & 2,821 & 1 & 0.069 \\
\hline High & 109 & 29 & 2,047 & $1.506(0.969-2.343)$ & \\
\hline \multicolumn{6}{|c|}{ ITGA11 } \\
\hline Low & 329 & 70 & 2,821 & 1 & 0.641 \\
\hline High & 109 & 28 & 1,910 & $1.111(0.713-1.731)$ & \\
\hline \multicolumn{6}{|l|}{$I T G A D$} \\
\hline Low & 329 & 73 & 2,475 & 1 & 0.801 \\
\hline High & 109 & 25 & 3,042 & $1.060(0.672-1.672)$ & \\
\hline \multicolumn{6}{|l|}{$I T G A E$} \\
\hline Low & 329 & 80 & 2,475 & 1 & 0.438 \\
\hline High & 109 & 18 & NA & 0.815(0.486-1.366) & \\
\hline \multicolumn{6}{|l|}{$I T G A L$} \\
\hline Low & 329 & 72 & 2,532 & 1 & 0.173 \\
\hline High & 109 & 26 & 2,134 & $1.370(0.871-2.156)$ & \\
\hline \multicolumn{6}{|c|}{ ITGAM } \\
\hline Low & 329 & 72 & 2,821 & 1 & 0.382 \\
\hline High & 109 & 26 & 2,134 & $1.222(0.779-1.917)$ & \\
\hline
\end{tabular}


Table II. Continued.

\begin{tabular}{lccccc}
\hline & & \multicolumn{3}{c}{ OS } \\
\cline { 3 - 5 } Gene & Patients (n=438) & No. of events & MST (days) & HR (95\% CI) & Adjusted P-value $^{\mathrm{a}}$ \\
\hline ITGAV & 329 & 81 & 2,532 & 1 & 0.327 \\
Low & 109 & 17 & 2,047 & $0.768(0.452-1.303)$ & \\
High & & & & 1 & 0.665 \\
ITGAX & 329 & 76 & 2,532 & $1.111(0.689-1.793)$ & \\
Low & 109 & 22 & 3,042 & & \\
High & & & & & \\
\hline
\end{tabular}

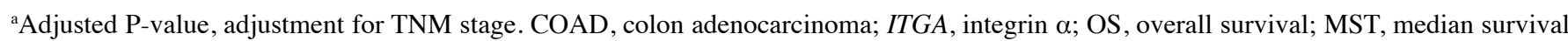
time; $95 \%$ CI, 95\% confidence interval; HR, hazards ratio; NA, not available.

A

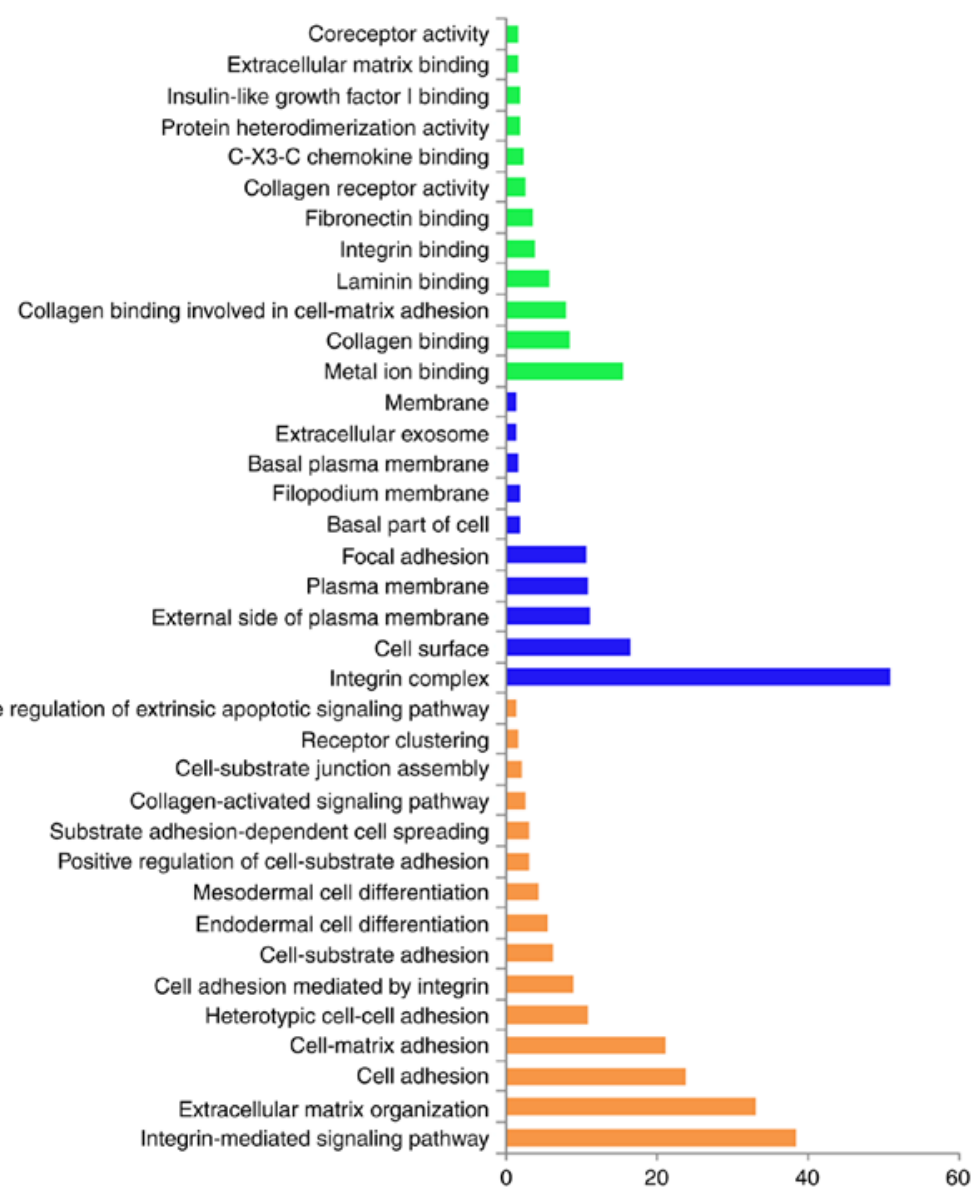

B

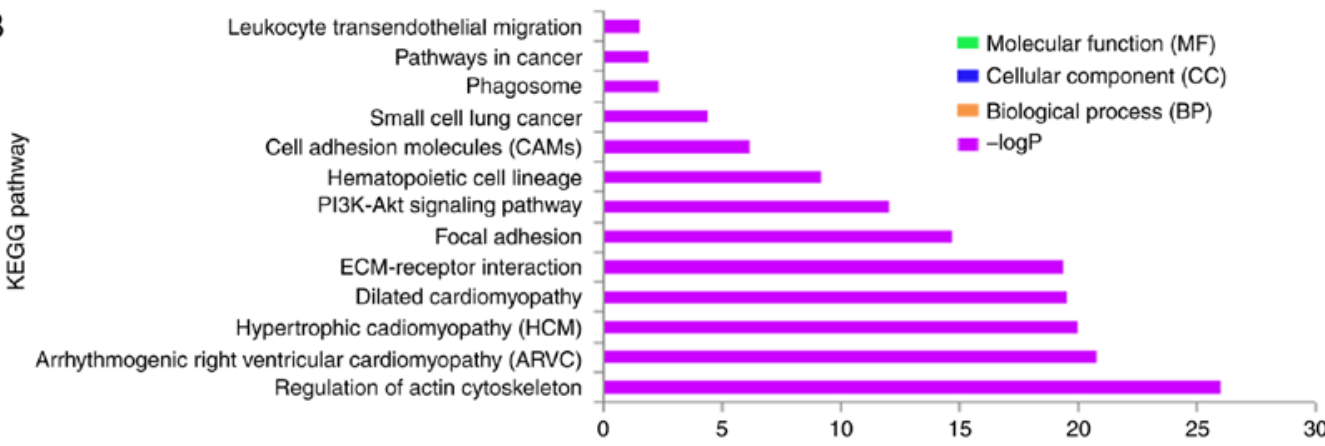

Figure 1. GO term and KEGG analysis of the ITGA subfamily genes. (A) GO term enrichment. (B) KEGG enrichment. GO, gene ontology; KEGG, Kyoto Encyclopedia of Genes and Genomes; ITGA, integrin $\alpha$. 
A

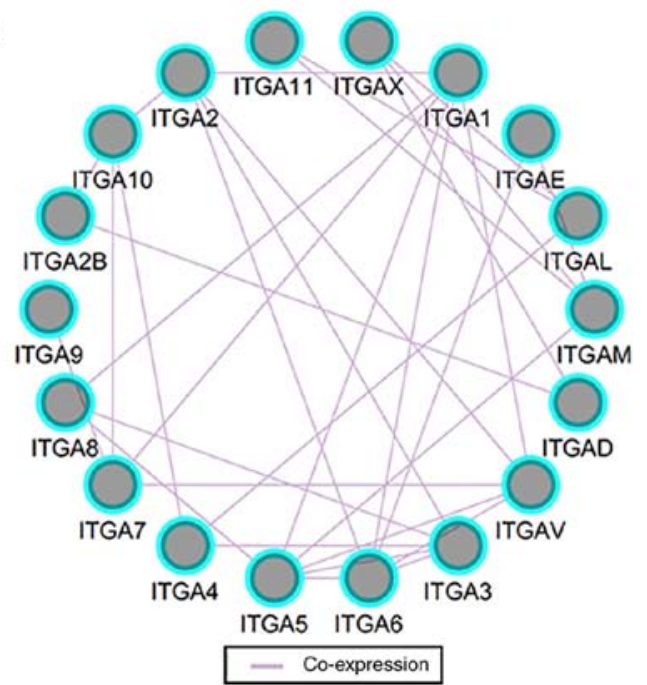

$\mathrm{B}$

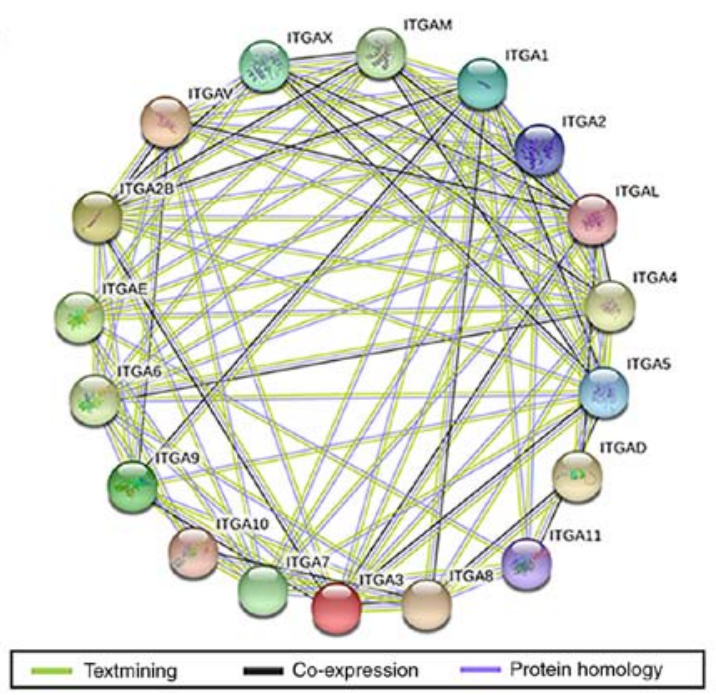

Figure 2. Gene-gene and protein-protein interaction networks of ITGA genes. (A) GeneMANIA interaction networks. (B) Protein-protein interaction networks. ITGA, integrin $\alpha$.
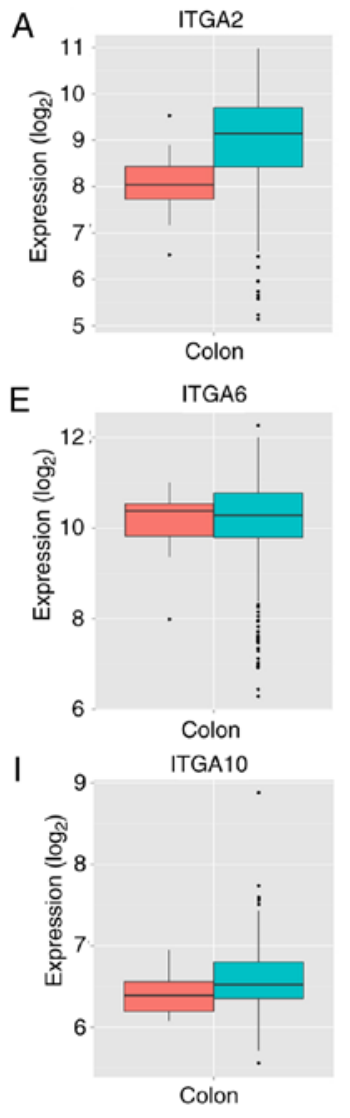

M

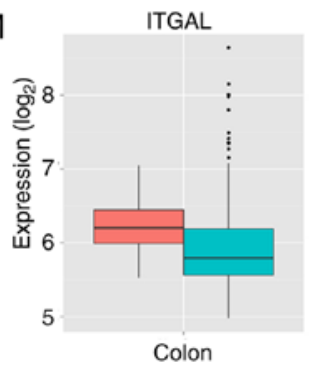

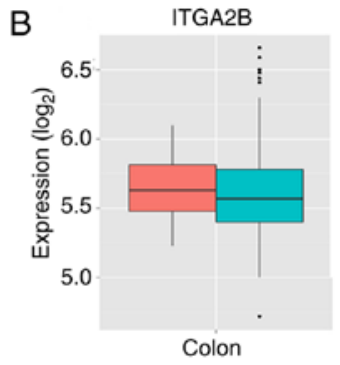

$\mathrm{F}$

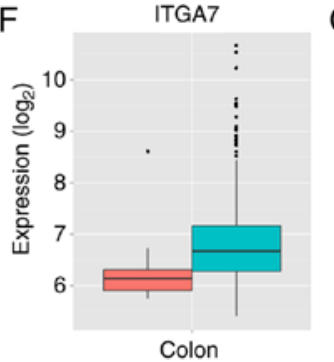

J
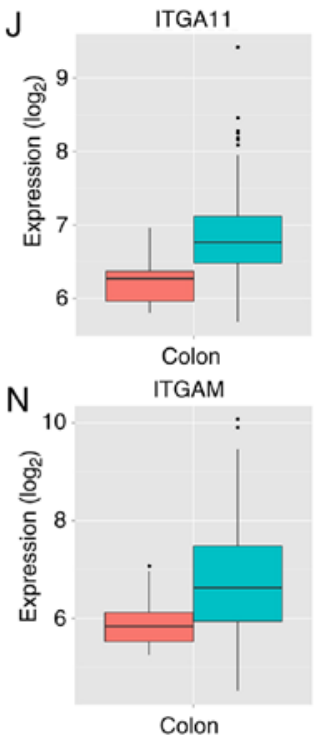

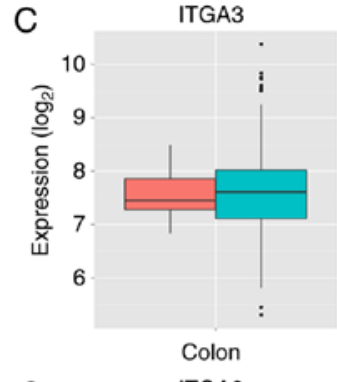

G
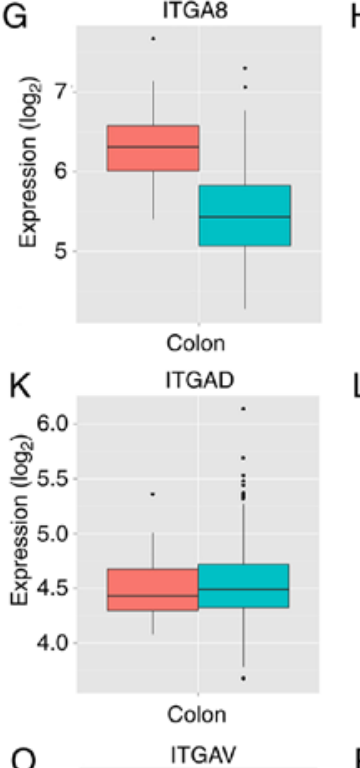

0

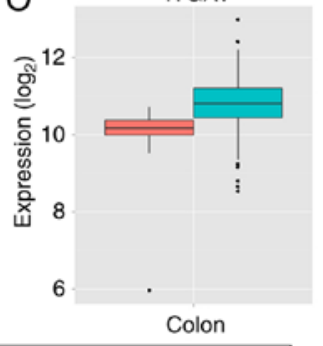

Colon
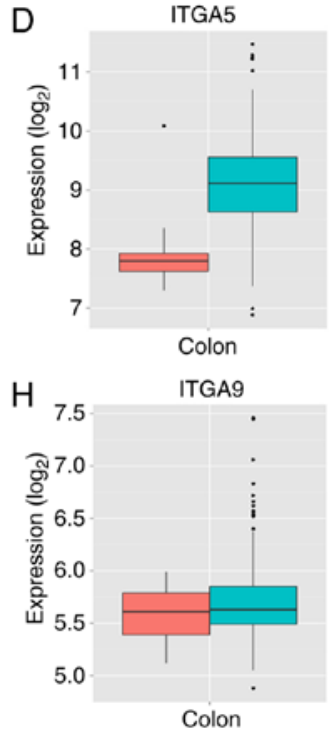

L
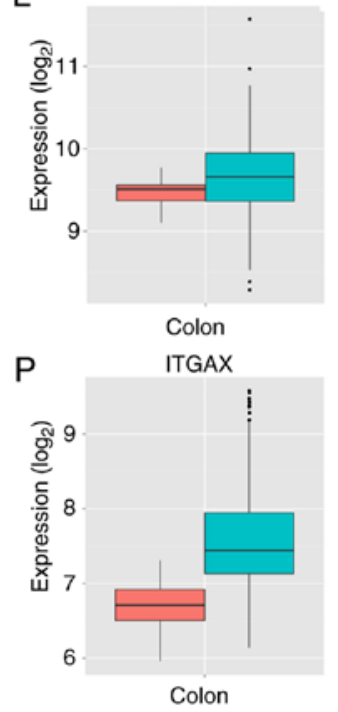

Tissue 追 Normal tissue 官Primary tumor

Figure 3. (A-P) The mRNA expression levels of ITGA genes in normal colon tissue and primary colon tumors. ITGA, integrin $\alpha$. 


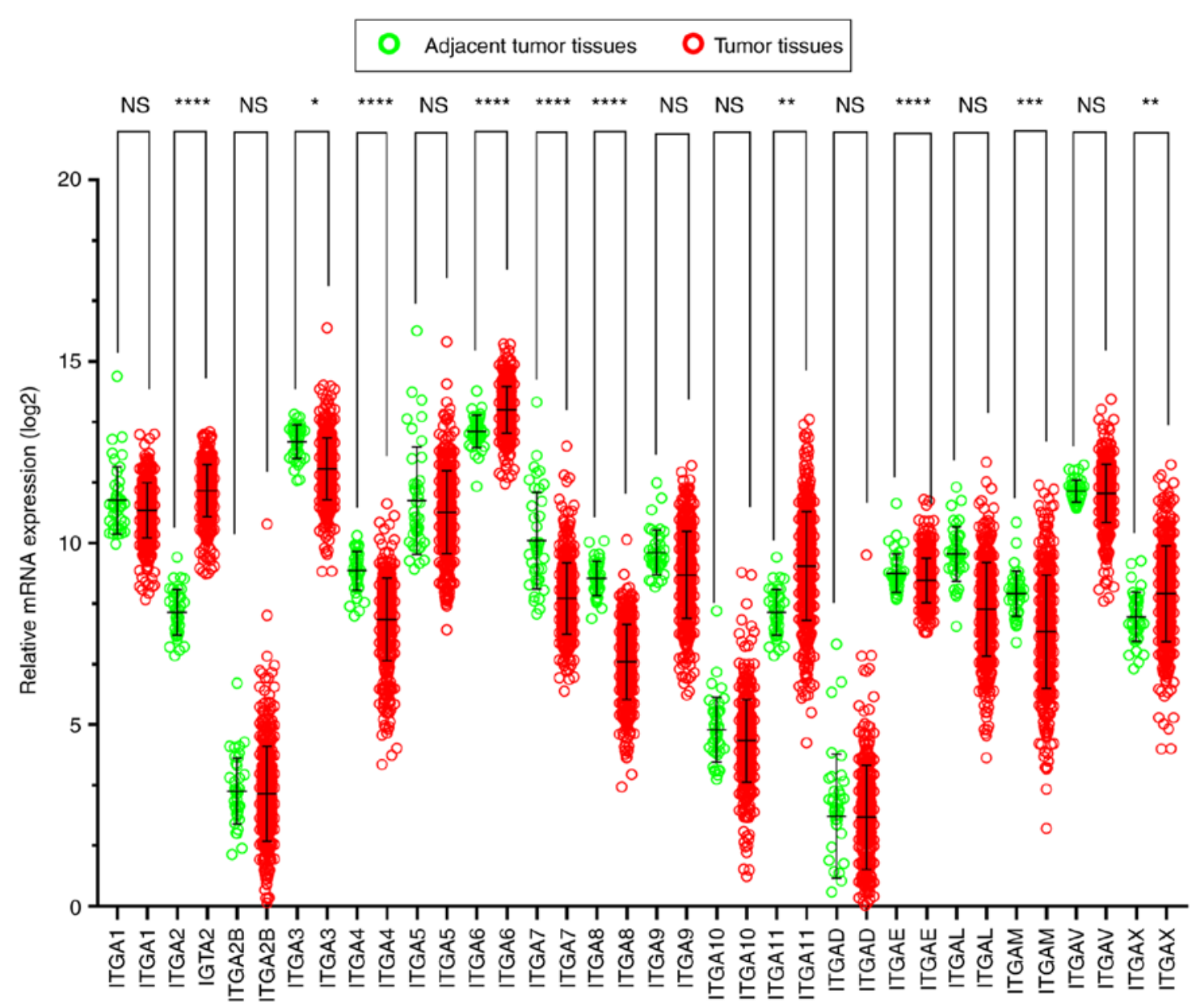

Figure 4. Gene expression distribution of ITGA genes in TCGA. NS, not significant; ${ }^{*} \mathrm{P}<0.05 ;{ }^{* *} \mathrm{P}<0.01 ;{ }^{* * *} \mathrm{P}<0.001 ;{ }^{* * * * *} \mathrm{P}<0.0001$. ITGA, integrin $\alpha$; TCGA, The Cancer Genome Atlas.

pathway and regulation of actin cytoskeleton (Fig. 1B and S2). The interaction networks of gene-gene and protein-protein indicated that ITGA genes had co-expression with each other and with complex gene-gene and protein-protein interaction networks (Fig. 2A and B).

Analysis of ITGA subfamily gene expression levels in tumor and adjacent normal tissues based on TCGA. Box plots of the expression levels of 16 genes are presented in Fig. 3 (ITGAI and ITGA4 are not presented). ITGA2B, ITGA6, ITGA 8 and $I T G A L$ were high in expression in adjacent normal tissues compared to tumor tissues, while the other 12 genes were high in tumor tissues compared to normal tissues.

The scatter diagrams were used to present the expression between the tumor and adjacent tissues (Fig. 4) and the results revealed that ITGA2B, ITGA5, ITGA10, ITGAD, ITGAE and $I T G A V$ exhibited no statistical significant differences, however the other genes significantly differed). It was also observed that the majority of genes were expressed at a significantly low level in tumor tissues, while the expression of adjacent normal tissues was high.

The possible potential application of ITGA genes in COAD tumor and adjacent tissues was further explored. The diagnostic ROC analysis of ITGA genes in the TCGA COAD cohort showed that ITGA2, ITGA3, ITGA4, ITGA6, ITGA7, ITGA8, ITGA11, ITGAL, ITGAM and ITGAX can serve as potential diagnostic biomarker for COAD (all $\mathrm{P}<0.05$ ). Notably, ITGA8 [AUC $(95 \%$ CI $)=0.989$ (0.980-0.997)] exhibited a high diagnostic value distinguishing tumor tissues and adjacent normal tissues of COAD $(\mathrm{P}<0.0001)$. All ROC curves are presented in Fig. 5.

Validation of ITGA8 expression in clinical samples. To investigate and further validate the possible function of ITGA8 expression in the clinical sample cohort, the paired t-test was performed between COAD tumors and adjacent normal tissues $(\mathrm{P}=0.041)$, and a scatter diagram was selected to compare the expression levels of the clinical sample cohort and TCGA cohort (Fig. 6A and B). The results indicated that both cohorts exhibited a significantly high expression level in adjacent normal tissues. Then, the diagnostic ROC curve was used to study the underlying role of ITGAS in clinical samples. The result revealed that $I T G A 8$ had a significant value $[\mathrm{P}=0.005$, AUC $(95 \%$ CI $)=0.704$ (0.577-0.831)]; (Fig. 6C).

Prognostic survival analysis. To further explore the survival values, survival analysis curves were drawn according to gene expression (Fig. 7). Only ITGA5 and ITGAIO exhibited statistical significance $(\mathrm{P}<0.05)$. Consequently, it was observed that a high level of ITGA5 and ITGA10 expression were linked with poor prognosis for OS (log-rank test, $\mathrm{P}=0.0045$ and $\mathrm{P}=0.0244)$. 

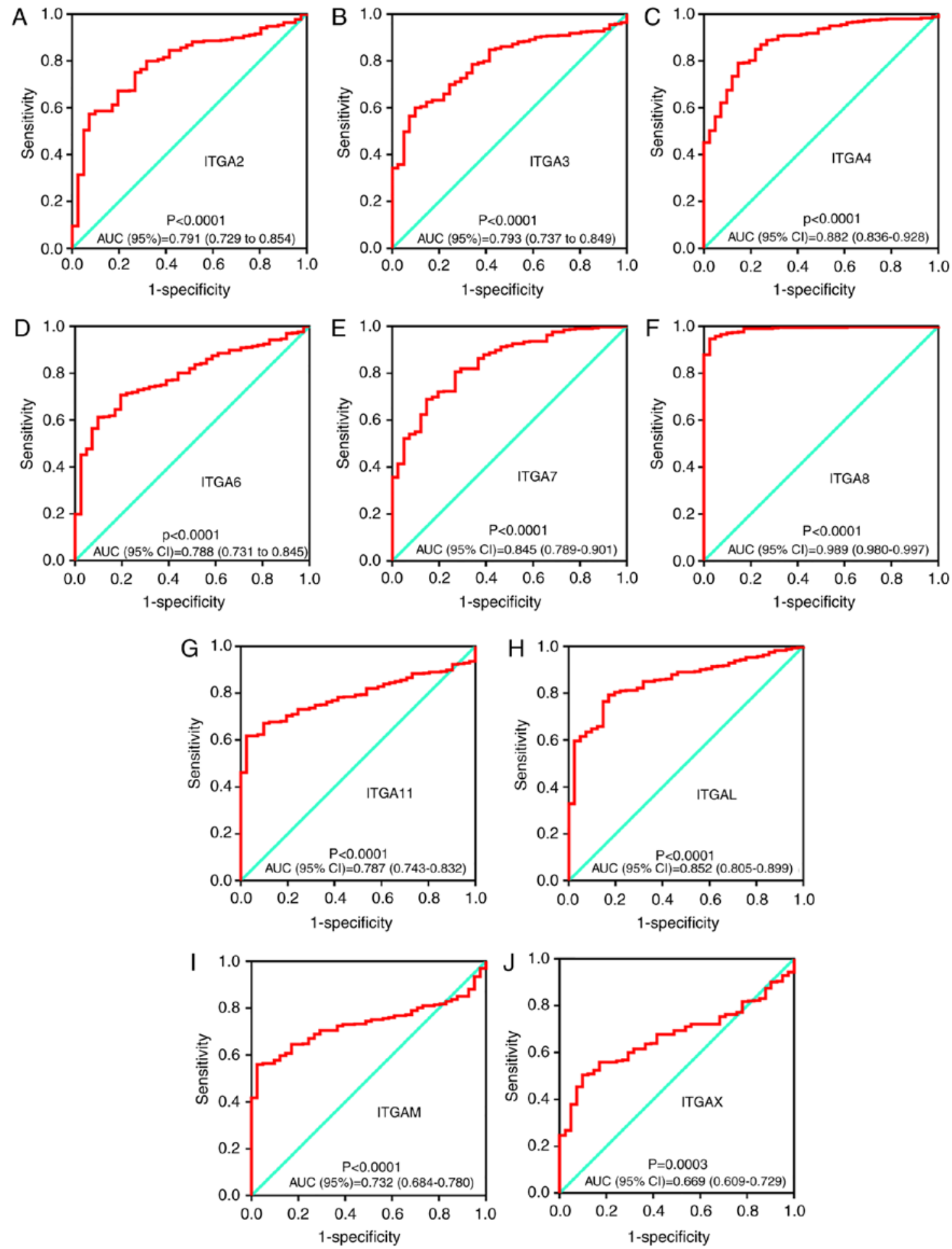

Figure 5. Diagnostic ROC curves of ITGA genes distinguishing COAD tumor tissues and adjacent normal tissues in a TCGA cohort. ROC curves of (A) ITGA2; (B) ITGA3; (C) ITGA4; (D) ITGA6; (E) ITGA7; (F) ITGA8; (G) ITGA11; (H) ITGAL; (I) ITGAM; and (J) ITGAX. ROC, receiver operating characteristic; ITGA, integrin $\alpha$; COAD, colon adenocarcinoma; TCGA, The Cancer Genome Atlas; AUC, area under the curve.

GSEA. In the present study, prognostic value of ITGA5 was assessed to investigate its potential in GO terms and KEGG pathways in COAD prognosis. GSEA revealed that the c5 gene sets indicated that the high expression of ITGA5 may be mostly enriched in ECM (Fig. 8A-I). In addition, the c2 gene sets were significantly involved in focal adhesion, the chemokine signaling pathway, pathways in cancer and ECM receptor interaction (Fig. 9A-I).

\section{Discussion}

As is recognized, the occurrence and development of tumors are caused by multiple factors, and the homeostasis of the internal environment is crucial. Integrins are a family of cell adhesion proteins that can mediate cell-cell, cell-extracellular matrix (ECM), cell-pathogen interactions and signaling through adhesion receptors $(7,12,44,45)$. The integrins are 

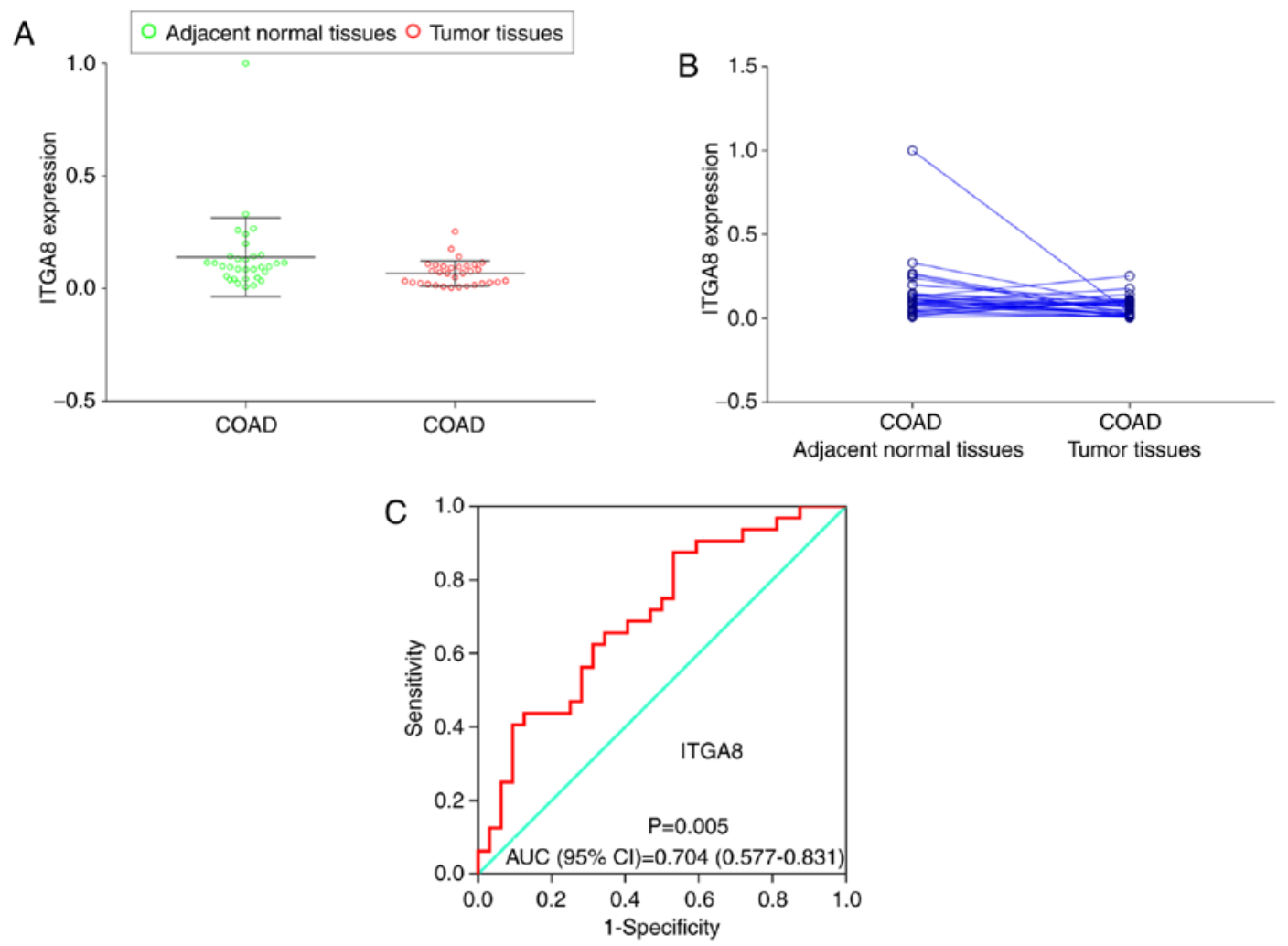

Figure 6. RT-qPCR is used to assess the relative expression of ITGA8 in COAD adjacent normal tissues and tumor tissues. (A and B) Gene relative expression distribution of ITGA8. (C) Diagnostic ROC of ITGA8 relative expression distribution. ITGA, integrin $\alpha$; COAD, colon adenocarcinoma; ROC, receiver operating characteristic; AUC, area under the curve.

the main receptors for extracellular matrix proteins like collagen, fibronectin and laminin. In addition, integrins play a fundamental role in various biological processes via cellular adhesion mechanisms $(10,46)$. The ITGA family is a subfamily of integrins, and certain previous studies had reported the relationship between the ITGA subfamily genes and colorectal cancer. Yang et al reported that ITGA2 was significantly overexpressed in both primary colon tumors and liver metastases with tissues from 43 patients as was determined by western blotting, immunohistochemistry and tissue microarray (47). The expression of ITGA3 was linked to other genes by cDNA Array and immunohistochemistry in colorectal cancer. It was revealed that ITGA3 was overexpressed in tumor tissues. In a study by Waisberg et al, the expression of ITGAV was assessed by PCR and immunohistochemistry in adult CRC patients $(n=114)$, and the results indicated that the overexpression of ITGAV was associated with higher progression and spread of CRC (48). ITGA subfamily genes have also been reported in other types of cancer. ITGAI was recently revealed to be associated with an invasive metastatic phenotype in hepatocellular and prostate cancers $(49,50)$. Other studies revealed that ITGA2 was expressed in gastric cancer (51), pancreatic cancer (52) and pancreatic ductal adenocarcinoma (PDAC) (53). In addition, ITGA10 was expressed in B-cell lymphoma (54) and ITGAII was expressed in breast cancer (55), lung squamous cancer (56) and neck squamous cell carcinoma (57).

However, there is little knowledge about the relationship between the ITGA subfamily genes and COAD. To the best of our knowledge, this was the first time that TCGA RNA sequencing dataset and PCR detection were used to investigate diagnostic and prognostic values of ITGA subfamily genes in COAD. The present results indicated that the mRNA expression levels of the ITGA subfamily genes were correlative with COAD in diagnosis and prognosis. Gene function enrichment analysis revealed that ITGA genes were significantly involved in biological processes, pathways of cell adhesion and the integrin-mediated signaling pathway. In addition, co-expression analysis revealed that ITGA genes were co-expressed with each other at both the gene and protein levels.

It was determined that ITGA2, ITGA6,ITGAII and ITGAX were significantly expressed at a high level in cancer tissues, while ITGA1, ITGA3, ITGA4, ITGA7, ITGA8, ITGA9, ITGAL and $I T G A M$ were significantly expressed at a high level in adjacent normal tissues in a TCGA cohort. The results of ROC curves revealed that ITGA 8 had a high diagnostic value [AUC $(95 \%$ CI $)=0.989(0.980-0.997)]$. Kok-Sin et al reported that ITAGA8 was considered as a potential diagnostic marker, serving as a tumor suppressor gene as determined via DNA methylation and gene expression profiling assays, in colorectal cancer (58). In a study by Yang et al, the ITGA 8 mRNA and protein levels were assessed in 483 LUAD tissues and 59 adjacent tissues, and the results indicated that the expression of ITGA 8 was downregulated in LUAD (59). Then, to further validate the expression of the ITGA 8 gene in cancer and adjacent tissues of COAD, RT-qPCR was performed, and the results revealed that ITGA 8 was significantly expressed at a high level in adjacent normal tissues of COAD. Thus, it was hypothesized that ITGA 8 may be a potential diagnostic marker in COAD. 
A
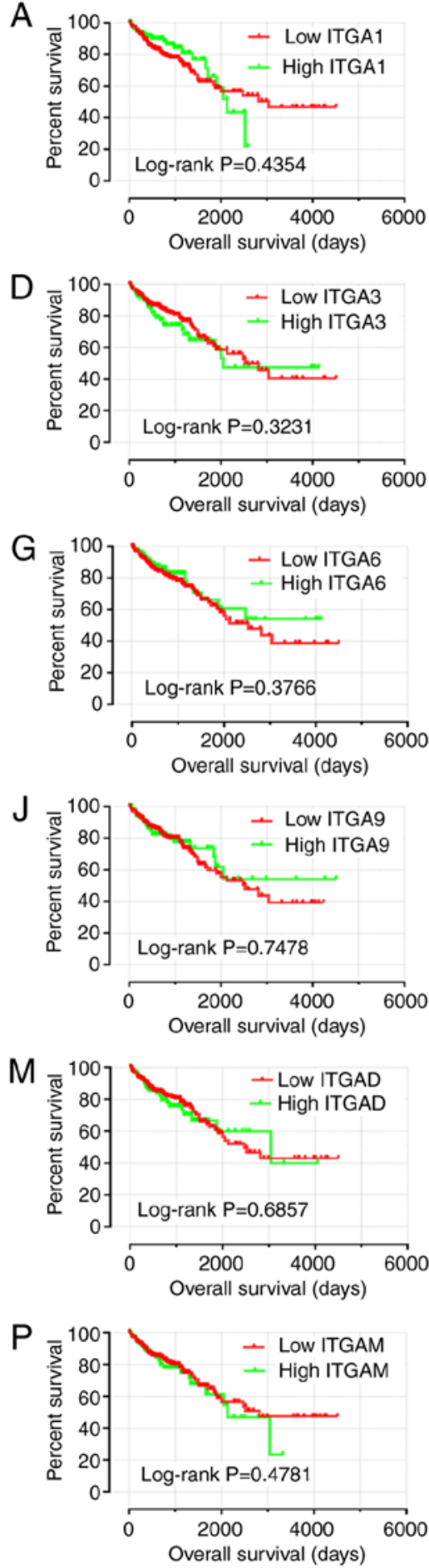
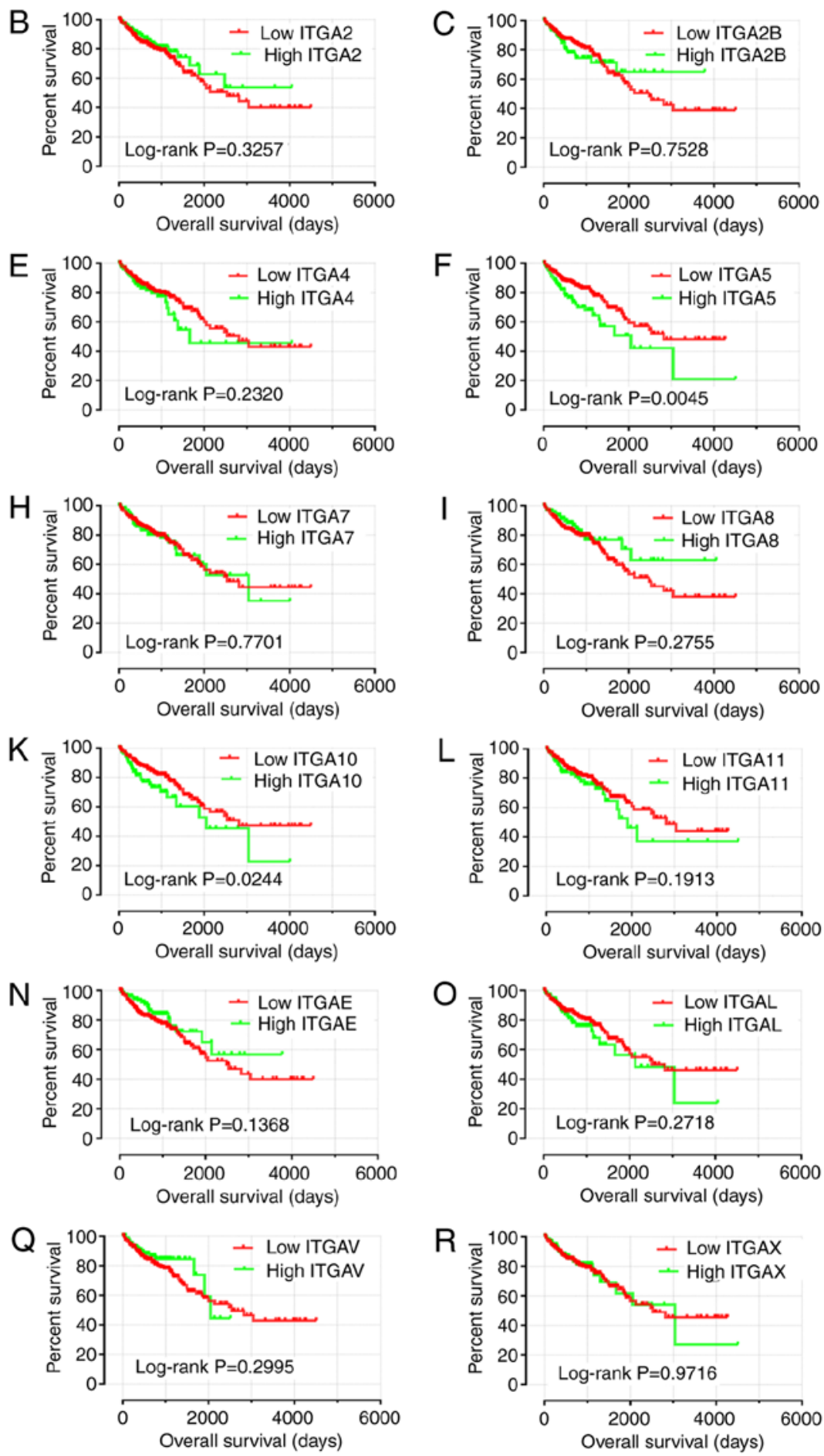

Figure 7. Kaplan-Meier survival curves for ITGA genes in COAD of TCGA cohort. OS stratified by (A) ITGA1, (B) ITGA2, (C) ITGA2B, (D) ITGA3, (E) ITGA4, (F) ITGA5, (G) ITGA6, (H) ITGA7, (I) ITGA8, (J) ITGA9, (K) ITGAI0, (L) ITGAI1, (M) ITGAD, (N) ITGAE, (O) ITGAL, (P) ITGAM, (Q) ITGAV, and (R) ITGAX. ITGA, integrin $\alpha$; COAD, colon adenocarcinoma; TCGA, The Cancer Genome Atlas; OS, overall survival.

Survival prognosis analysis results revealed that the high expression levels of ITGA5 and ITGAI0 were associated with poor prognosis, while Kaplan-Meier curves from multivariate survival analysis revealed that the low expression of ITGA5 was linked to favorable prognosis of COAD OS in the TCGA cohort. Especially ITGA5 was an independent prognosis factor for OS of COAD patients. However, previous studies revealed that overexpression of ITGA5 indicated poor prognosis. A study by Shang et al revealed that low expression of ITGA5 indicated a good overall survival (OS) or relapse-free survival (RFS) of HBV-related HCC patients (60). Research by Haider et al revealed that high expression of ITGA5 was associated with a short survival time of pancreatic ductal adenocarcinoma (PDAC) patients (61). In addition, the results from a study by Yan $e t$ al indicated that the upregulated expression of ITGA5 reduced the overall survival of gastric cancer (GC) patients (62). Similar results were also reported in non-small 
A

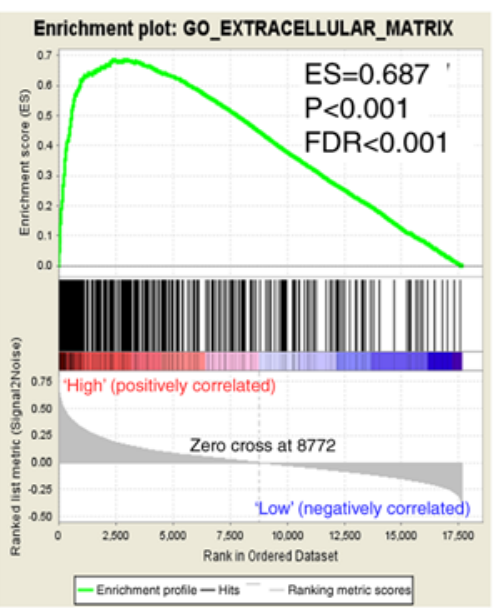

$\mathrm{D}$

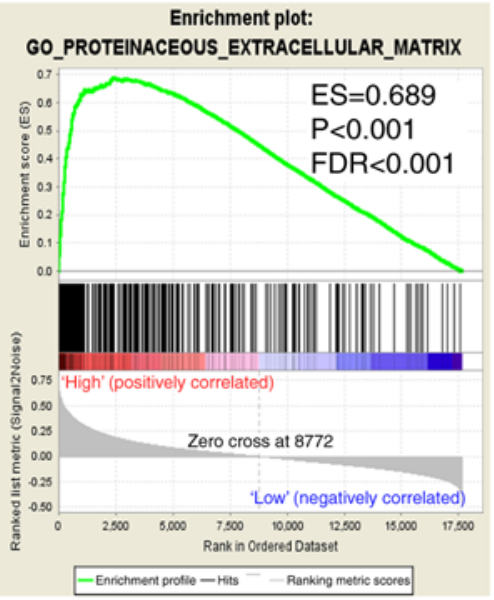

G

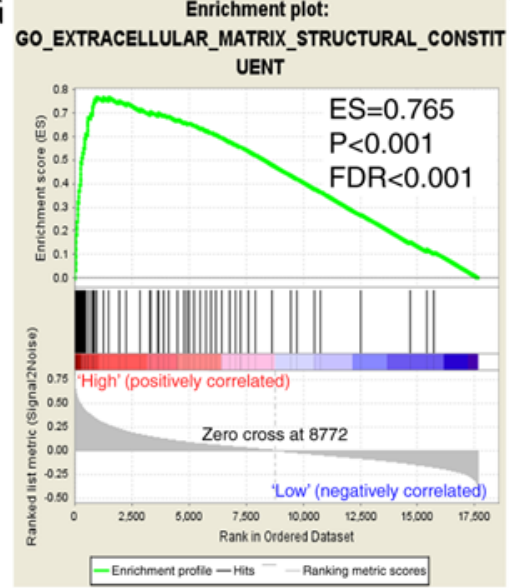

B

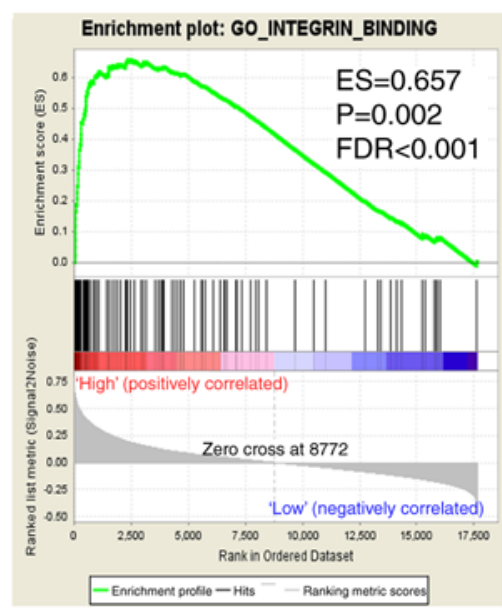

E

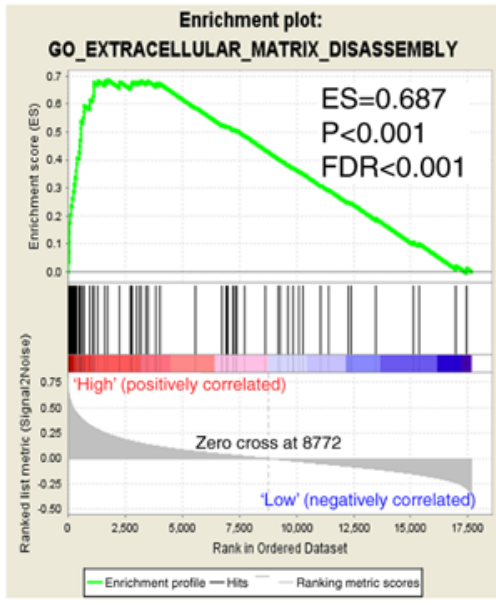

$\mathrm{H}$

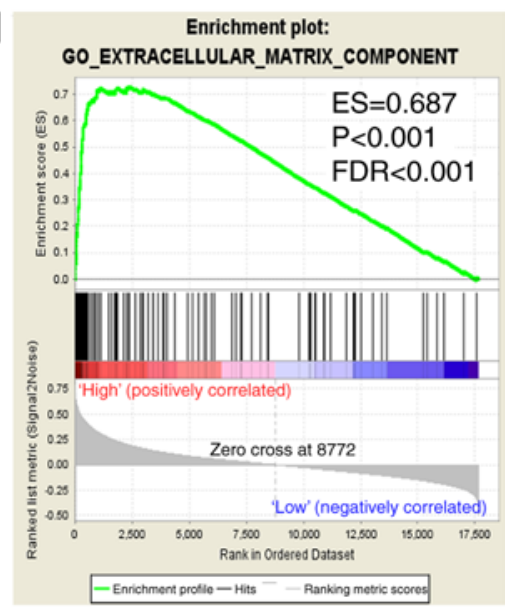

C Enrichment plot: GO_REGULATION_OF_CHEMOTAXIS

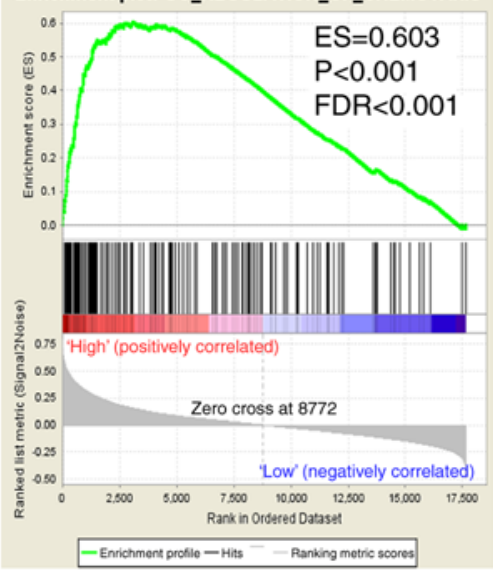

$\mathrm{F}$

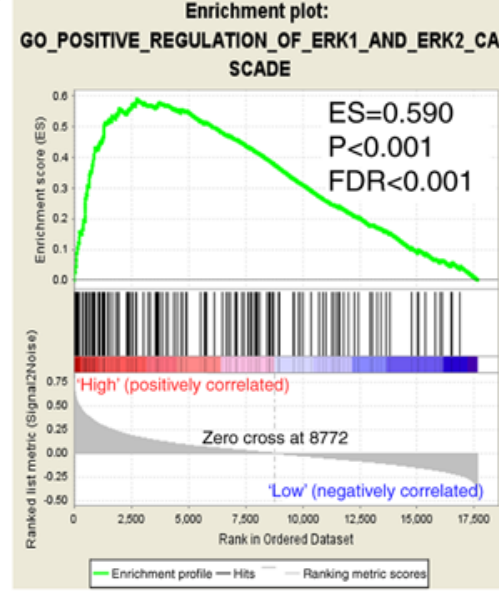

| Enrichment plot: GO_GROWTH_FACTOR_BINDING

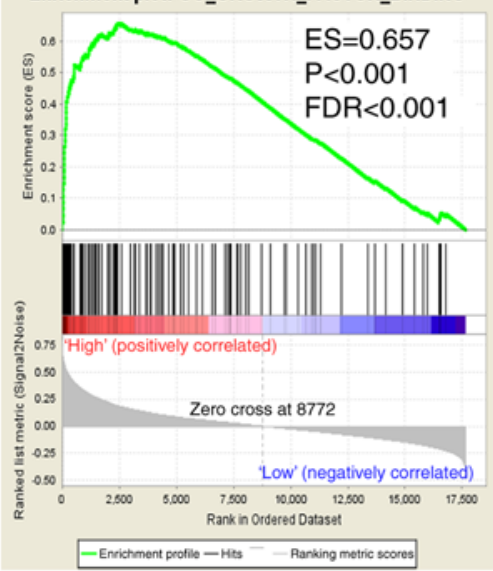

Figure 8. GSEA results of ITGA5 in TCGA COAD patients. (A-I) GSEA results of c5 reference gene sets for high-ITGA5 expression groups. GSEA, gene set enrichment analysis; ITGA5, integrin $\alpha 5$; TCGA, The Cancer Genome Atlas; COAD, colon adenocarcinoma.

cell lung cancer (NSCLC) (63) and glioblastoma cell invasion (64).

The results of GSEA in the present study indicated that ITGA5 (also known as FNRA, CD49e, VLA-5 and VLA5A) was markedly associated with the survival and progression of $\mathrm{COAD}$, and the underlying mechanism of focal adhesion, ECM receptor interaction and extracellular matrix (ECM) were associated with its biological functions. Integrin $\alpha$ subunit and $\beta$ subunit form heterodimeric integral membrane proteins that function in cell surface adhesion and signaling (16). Previous studies have reported that ITGA5 mediated cell adhesion and migration in human hepatocarcinoma cells by activating focal adhesion kinase (FAK) (65). A study by Yang and Wang revealed that ITGA5 participated in pathways involving focal adhesion and ECM-receptor interaction in osteosarcoma (66). In addition, ITGA5 may be involved in bladder cancer progression by extracellular matrix-receptor interaction and focal adhesion (67). In the present study, the results of GSEA indicated that ITGA5 may serve as an important adhesion molecule through its adhesion mechanism in COAD. To be 
A

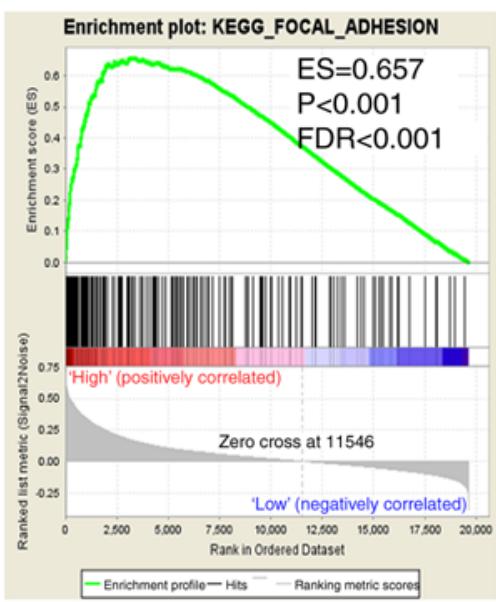

D

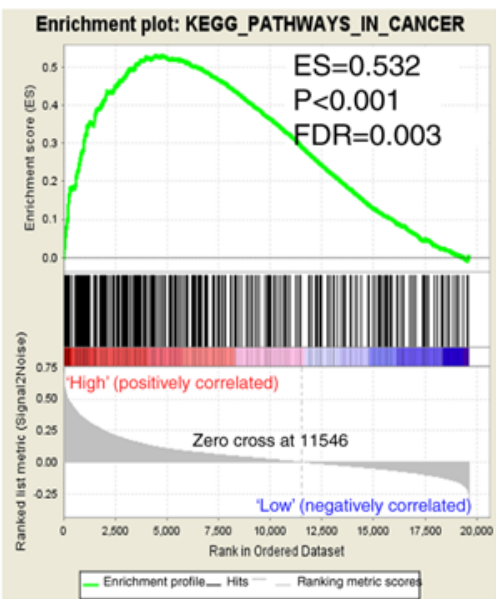

G

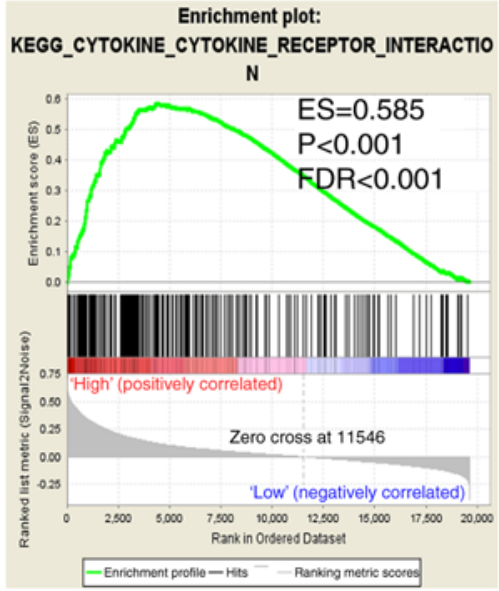

B

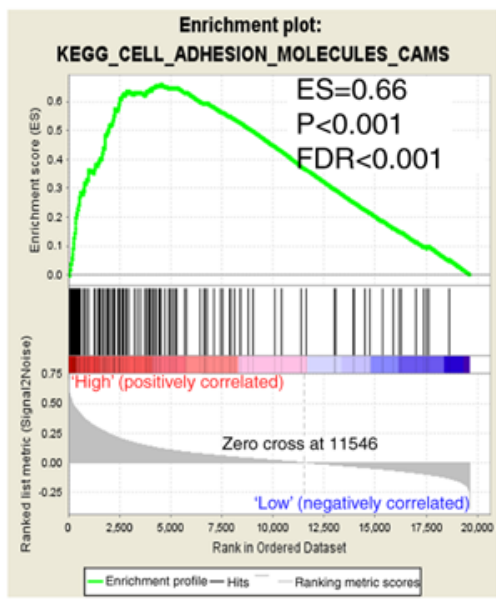

$E$

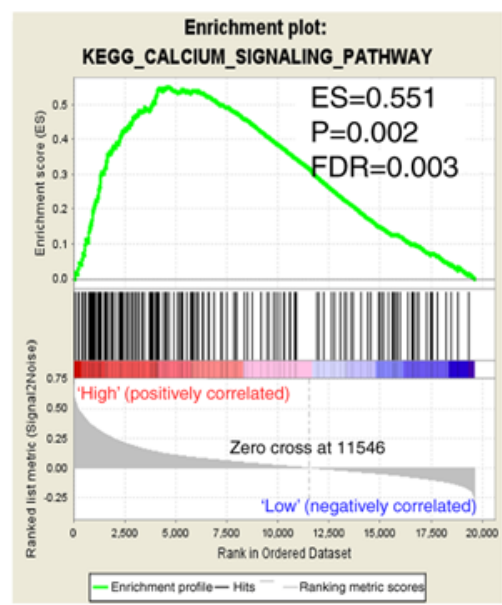

$\mathrm{H}$

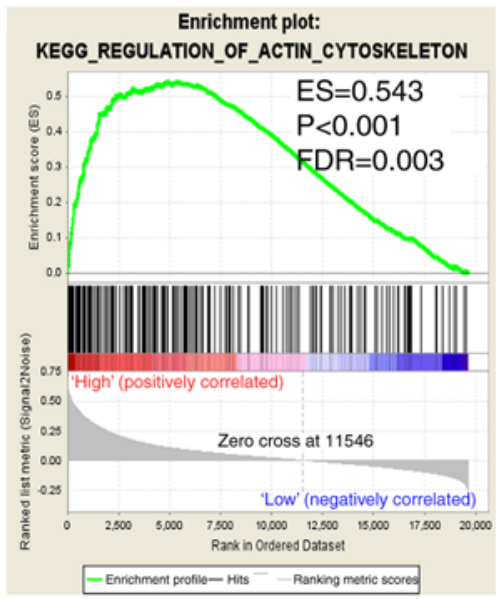

C Enrichment plot: KEGG_ECM_RECEPTOR_INTERACTION

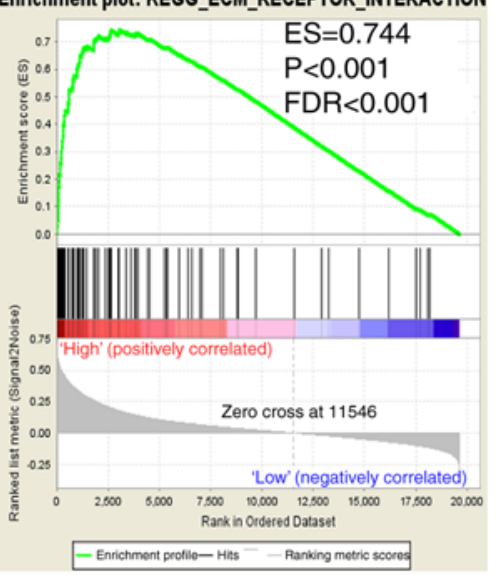

F
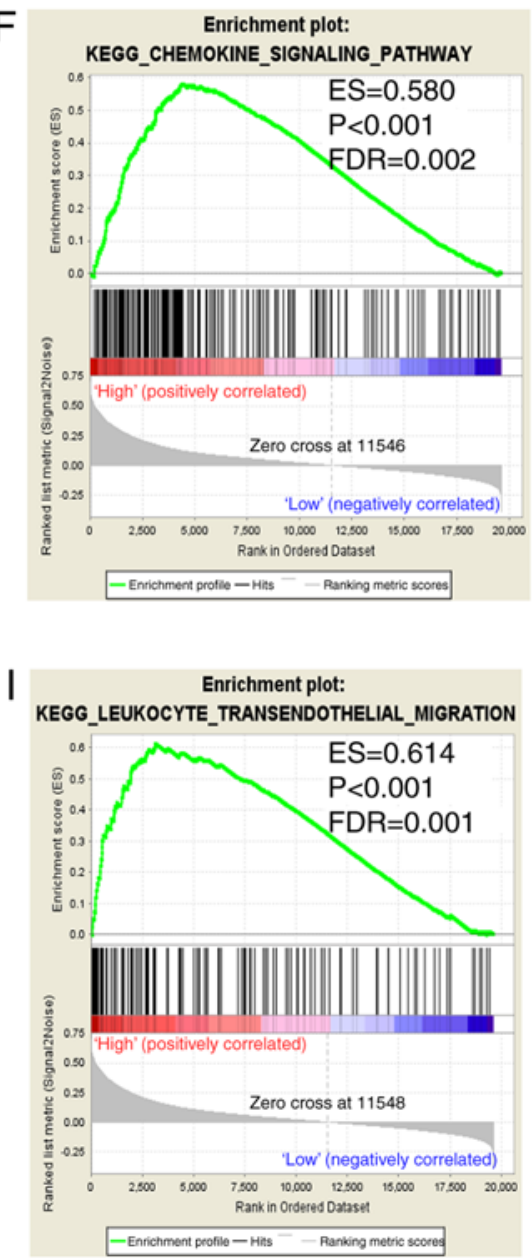

Figure 9. GSEA results of ITGA5 in TCGA COAD patients. (A-I) GSEA results of c2 reference gene sets for high-ITGA5 expression groups. GSEA, gene set enrichment analysis; ITGA5, integrin $\alpha 5$; TCGA, The Cancer Genome Atlas; COAD, colon adenocarcinoma.

specific, ITGA5 may act on COAD via the FAK signaling pathway and ECM receptor signaling pathway. However, these results require further research to be confirmed.

Although the present study was the first to reveal the role of the ITGA subfamily in the diagnosis and prognosis of COAD, it still has certain limitations. First, all the information was obtained from open databases, and the medical parameters were incomplete. Other potential influencing factors like tumor location, tumor size, lymphatic metastasis, and venous metastasis were not included. Second, disease-free survival should be listed as a factor to assess COAD prognosis. Third, the study required a larger multi-center and multi-regional as well as a multi-ethnic sample population. Fourth, the present study required further investigation at the protein level and COAD prognosis prediction, as well as further in vivo and in vitro experimental validation.

In conclusion, the present study revealed that the ITGA subfamily mRNA expression was associated with the diagnosis 
and prognosis of COAD. Combined with ROC curves and RT-qPCR verification, the ITGA8 expression level may be a potential diagnostic marker of COAD. In addition, survival analysis indicated that the expression of ITGA5 may serve as a prognostic biomarker of COAD. However, the present results still require further exploration and verification in the future.

\section{Acknowledgements}

The authors would like to acknowledge the support of the National Key Clinical Specialty Programs (General Surgery and Oncology) and the Key Laboratory of Early Prevention and Treatment for Regional High-Incidence-Tumor (Guangxi Medical University), Ministry of Education, China. We would also like to thank The Cancer Genome Atlas (https://cancergenome.nih.gov/) for sharing the COAD dataset on open access.

\section{Funding}

The present study was sponsored in part by the 2018 Innovation Project of Guangxi Graduate Education (YCBZ2018036) and the Innovation Project of Guangxi Graduate Education (JGY2018037).

\section{Availability of data and materials}

The analyzed datasets generated during the study are available from The Cancer Genome Atlas (https://portal.gdc.cancer.gov/).

\section{Authors' contributions}

YZG and GTR wrote the manuscript. YZG and FG made substantial contributions to the conception, design and intellectual content of the studies. YZG, GTR, XWL, XKW, CL and SW made key contributions to the analysis and interpretation of data. All authors read and approved the final manuscript and agree to be accountable for all aspects of the research in ensuring that the accuracy or integrity of any part of the work are appropriately investigated and resolved.

\section{Ethics approval and consent to participate}

All patients signed an informed consent form, and the experimental protocol was approved by the Ethics Committee of the First Affiliated Hospital of Guangxi Medical University [no. 2019(KY-E-001)].

\section{Patient consent for publication}

Not applicable.

\section{Competing interests}

The authors declare that they have no competing interests.

\section{References}

1. Bray F, Ferlay J, Soerjomataram I, Siegel RL, Torre LA and Jemal A: Global cancer statistics 2018: GLOBOCAN estimates of incidence and mortality worldwide for 36 cancers in 185 countries. CA Cancer J Clin 68: 394-424, 2018.
2. Zhang Z, Qian W, Wang S, Ji D, Wang Q, Li J, Peng W, Gu J, $\mathrm{Hu}$ T, Ji B, et al: Analysis of lncRNA-Associated ceRNA network reveals potential lncRNA biomarkers in human colon adenocarcinoma. Cell Physiol Biochem 49: 1778-1791, 2018.

3. Thrumurthy SG, Thrumurthy SS, Gilbert CE, Ross P and Haji A: Colorectal adenocarcinoma: Risks, prevention and diagnosis. BMJ 354: i3590, 2016.

4. Jiang H, Du J, Gu J, Jin L, Pu Y and Fei B: A 65 gene signature for prognostic prediction in colon adenocarcinoma. Int J Mol Med 41: 2021-2027, 2018.

5. Yang Y, Li XJ, Li P and Guo XT: MicroRNA-145 regulates the proliferation, migration and invasion of human primary colon adenocarcinoma cells by targeting MAPK1. Int J Mol Med 42: 3171-3180, 2018.

6. Tsukuda K, Tanino M, Soga H, Shimizu N and Shimizu K: A novel activating mutation of the K-ras gene in human primary colon adenocarcinoma. Biochem Biophys Res Commun 278: 653-658, 2000

7. Arnaout MA: Integrin structure: New twists and turns in dynamic cell adhesion. Immunol Rev 186: 125-140, 2002.

8. Tadokoro S, Shattil SJ, Eto K, Tai V, Liddington RC, de Pereda JM, Ginsberg MH and Calderwood DA: Talin binding to integrin beta tails: A final common step in integrin activation. Science 302: 103-106, 2003.

9. Ginsberg MH, Partridge A and Shattil SJ: Integrin regulation. Curr Opin Cell Biol 17: 509-516, 2005.

10. Takada Y, Ye X and Simon S: The integrins. Genome Biol 8: 215 , 2007.

11. Campbell ID and Humphries MJ: Integrin structure, activation, and interactions. Cold Spring Harb Perspect Biol 3: a004994, 2011.

12. Hynes RO: Integrins: Bidirectional, allosteric signaling machines. Cell 110: 673-687, 2002.

13. Larson RS, Corbi AL, Berman L and Springer T: Primary structure of the leukocyte function-associated molecule-1 alpha subunit: An integrin with an embedded domain defining a protein superfamily. J Cell Biol 108: 703-712, 1989.

14. Humphries JD, Byron A and Humphries MJ: Integrin ligands at a glance. J Cell Sci 119: 3901-3903, 2006.

15. Oxvig Cand SpringerTA: Experimental support for a beta-propeller domain in integrin alpha-subunits and a calcium binding site on its lower surface. Proc Natl Acad Sci USA 95: 4870-4875, 1998.

16. Desgrosellier JS and Cheresh DA: Integrins in cancer: Biological implications and therapeutic opportunities. Nat Rev Cancer 10: 9-22, 2010

17. Goodman SL and Picard M: Integrins as therapeutic targets. Trends Pharmacol Sci 33: 405-412, 2012.

18. Shattil SJ, Kim C and Ginsberg MH: The final steps of integrin activation: The end game. Nat Rev Mol Cell Biol 11: 288-300, 2010.

19. Moser M, Nieswandt B, Ussar S, Pozgajova M and Fassler R: Kindlin-3 is essential for integrin activation and platelet aggregation. Nat Med 14: 325-330, 2008.

20. Shen B, Delaney MK and Du X: Inside-out, outside-in, and inside-outside-in: $\mathrm{G}$ protein signaling in integrin-mediated cell adhesion, spreading, and retraction. Curr Opin Cell Biol 24: 600-606, 2012

21. Legate KR, Wickstrom SA and Fassler R: Genetic and cell biological analysis of integrin outside-in signaling. Genes Dev 23: 397-418, 2009.

22. Schwartz MA and Ginsberg MH: Networks and crosstalk: Integrin signalling spreads. Nat Cell Biol 4: E65-E68, 2002.

23. Hehlgans S, Haase M and Cordes N: Signalling via integrins: Implications for cell survival and anticancer strategies. Biochim Biophys Acta 1775: 163-180, 2007.

24. Ryu J, Koh Y, Park H, Kim DY, Kim DC, Byun JM, Lee HJ and Yoon SS: Highly expressed integrin-alpha8 induces epithelial to mesenchymal transition-like features in multiple myeloma with early relapse. Mol Cells 39: 898-908, 2016.

25. Guo WH, Bian JJ, Tian GF, Lyu ZX, Gui YX and Ye L: Expression of fermintin family homologous protein 2 in non-small cell lung cancer and its clinical significance. Zhonghua Bing Li Xue Za Zhi 47: 780-783, 2018 (In Chinese; Abstract available in Chinese from the publisher).

26. Haas TL, Sciuto MR, Brunetto L, Valvo C, Signore M, Fiori ME, di Martino S, Giannetti S, Morgante L, Boe A, et al: Integrin alpha7 is a functional marker and potential therapeutic target in glioblastoma. Cell stem cell 21: 35-50.e9, 2017.

27. Gong L, Zheng Y, Liu S and Peng Z: Fibronectin regulates the dynamic formation of ovarian cancer multicellular aggregates and the expression of integrin receptors. Asian Pac J Cancer Prev 19: 2493-2498, 2018. 
28. Chang HW, Yen CY, Chen CH, Tsai JH, Tang JY, Chang YT, Kao YH, Wang YY, Yuan SF and Lee SY: Evaluation of the mRNA expression levels of integrins alpha3, alpha5, beta1 and beta6 as tumor biomarkers of oral squamous cell carcinoma. Oncol Lett 16: 4773-4781, 2018.

29. Ji J, Chen H, Liu XP, Wang YH, Luo CL, Zhang WW, Xie W and Wang FB: A miRNA combination as promising biomarker for hepatocellular carcinoma diagnosis: A study based on bioinformatics analysis. J Cancer 9: 3435-3446, 2018

30. Huang da W, Sherman BT and Lempicki RA: Bioinformatics enrichment tools: Paths toward the comprehensive functional analysis of large gene lists. Nucleic Acids Res 37: 1-13, 2009.

31. Ashburner M, Ball CA, Blake JA, Botstein D, Butler H, Cherry JM, Davis AP, Dolinski K, Dwight SS, Eppig JT, et al: Gene ontology: Tool for the unification of biology. The Gene Ontology Consortium. Nat Genet 25: 25-29, 2000.

32. Gene Ontology Consortium: The Gene Ontology (GO) project in 2006. Nucleic Acids Res 34: D322-D326, 2006.

33. Maere S, Heymans K and Kuiper M: BiNGO: A cytoscape plugin to assess overrepresentation of gene ontology categories in biological networks. Bioinformatics 21: 3448-3449, 2005.

34. Mostafavi S, Ray D, Warde-Farley D, Grouios C and Morris Q: GeneMANIA: A real-time multiple association network integration algorithm for predicting gene function. Genome Biol 9 (Suppl 1): S4, 2008.

35. Szklarczyk D, Morris JH, Cook H, Kuhn M, Wyder S, Simonovic M, Santos A, Doncheva NT, Roth A, Bork P, et al: The STRING database in 2017: Quality-controlled protein-protein association networks, made broadly accessible. Nucleic Acids Res 45: D362-D368, 2017.

36. Franceschini A, Szklarczyk D, Frankild S, Kuhn M, Simonovic M, Roth A, Lin J, Minguez P, Bork P, von Mering C and Jensen LJ: STRING v9.1: Protein-protein interaction networks, with increased coverage and integration. Nucleic Acids Res 41: D808-D815, 2013

37. Wang X, Yu T, Liao X, Yang C, Han C, Zhu G, Huang K, Yu L, Qin W, Su H, et al: The prognostic value of CYP2C subfamily genes in hepatocellular carcinoma. Cancer Med 7: 966-980, 2018.

38. Livak KJ and Schmittgen TD: Analysis of relative gene expression data using real-time quantitative PCR and the 2(-Delta Delta C(T)) method. Methods 25: 402-408, 2001.

39. Subramanian A, Tamayo P, Mootha VK, Mukherjee S, Ebert BL, Gillette MA, Paulovich A, Pomeroy SL, Golub TR, Lander ES and Mesirov JP: Gene set enrichment analysis: A knowledge-based approach for interpreting genome-wide expression profiles. Proc Natl Acad Sci USA 102: 15545-15550, 2005.

40. Mootha VK, Lindgren CM, Eriksson KF, Subramanian A, Sihag S, Lehar J, Puigserver P, Carlsson E, Ridderstrale M, Laurila E, et al: PGC-1alpha-responsive genes involved in oxidative phosphorylation are coordinately downregulated in human diabetes. Nat Genet 34: 267-273, 2003.

41. Liberzon A, Birger C, Thorvaldsdottir H, Ghandi M, Mesirov JP and Tamayo P: The molecular signatures database (MSigDB) hallmark gene set collection. Cell Syst 1: 417-425, 2015

42. Reiner A, Yekutieli D and Benjamini Y: Identifying differentially expressed genes using false discovery rate controlling procedures. Bioinformatics 19: 368-375, 2003.

43. Benjamini Y, Drai D, Elmer G, Kafkafi N and Golani I: Controlling the false discovery rate in behavior genetics research. Behav Brain Res 125: 279-284, 2001.

44. Caswell PT and Norman JC: Integrin trafficking and the control of cell migration. Traffic 7: 14-21, 2006.

45. Xiong J, Balcioglu HE and Danen EH: Integrin signaling in control of tumor growth and progression. Int J Biochem Cell Biol 45: 1012-1015, 2013.

46. Felding-Habermann B, Mueller BM, Romerdahl CA and Cheresh DA: Involvement of integrin alpha $\mathrm{V}$ gene expression in human melanoma tumorigenicity. J Clin Invest 89: 2018-2022, 1992

47. Yang Q, Bavi P, Wang JY and Roehrl MH: Immuno-proteomic discovery of tumor tissue autoantigens identifies olfactomedin 4 $\mathrm{CD} 11 \mathrm{~b}$, and integrin alpha-2 as markers of colorectal cancer with liver metastases. J Proteomics 168: 53-65, 2017.

48. Waisberg J, De Souza Viana L, Affonso Junior RJ, Silva SR, Denadai MV, Margeotto FB, De Souza CS and Matos D: Overexpression of the ITGAV gene is associated with progression and spread of colorectal cancer. Anticancer Res 34: 5599-5607, 2014.

49. Liu X, Tian H, Li H, Ge C, Zhao F, Yao M and Li J: Derivate Isocorydine (d-ICD) suppresses migration and invasion of hepatocellular carcinoma cell by downregulating ITGA1 expression. Int J Mol Sci 18 pii: E514, 2017.
50. Rosenberg EE, Prudnikova TY, Zabarovsky ER, Kashuba VI and Grigorieva EV: D-glucuronyl C5-epimerase cell type specifically affects angiogenesis pathway in different prostate cancer cells. Tumour Biol 35: 3237-3245, 2014.

51. Chuang YC, Wu HY, Lin YL, Tzou SC, Chuang CH, Jian TY, Chen PR, Chang YC, Lin CH, Huang TH, et al: Blockade of ITGA2 induces apoptosis and inhibits cell migration in gastric cancer. Biol Proced Online 20: 10, 2018.

52. Gong J, Lu X, Xu J, Xiong W, Zhang $\mathrm{H}$ and $\mathrm{Yu} \mathrm{X}$ : Coexpression of UCA1 and ITGA2 in pancreatic cancer cells target the expression of miR-107 through focal adhesion pathway. J Cell Physiol 234: 12884-12896, 2019.

53. Lu Y, Li C, Chen $\mathrm{H}$ and Zhong W: Identification of hub genes and analysis of prognostic values in pancreatic ductal adenocarcinoma by integrated bioinformatics methods. Mol Biol Rep 45: 1799-1807, 2018.

54. Lemma SA, Kuusisto M, Haapasaari KM, Sormunen R, Lehtinen T, Klaavuniemi T, Eray M, Jantunen E, Soini Y, Vasala K, et al: Integrin alpha 10, CD44, PTEN, cadherin-11 and lactoferrin expressions are potential biomarkers for selecting patients in need of central nervous system prophylaxis in diffuse large B-cell lymphoma. Carcinogenesis 38: 812-820, 2017.

55. Pan Y, Liu G, Yuan Y, Zhao J, Yang Y and Li Y: Analysis of differential gene expression profile identifies novel biomarkers for breast cancer. Oncotarget 8: 114613-114625, 2017.

56. Zhang R, Zhang TT, Zhai GQ, Guo XY, Qin Y, Gan TQ, Zhang Y, Chen G, Mo WJ and Feng ZB: Evaluation of the HOXA11 level in patients with lung squamous cancer and insights into potential molecular pathways via bioinformatics analysis. World J Surg Oncol 16: 109, 2018.

57. Parajuli H, The MT, Abrahamsen S, Christoffersen I, Neppelberg E, Lybak S, Osman T, Johannessen AC, Gullberg D, Skarstein $\mathrm{K}$ and Costea DE: Integrin alpha11 is overexpressed by tumour stroma of head and neck squamous cell carcinoma and correlates positively with alpha smooth muscle actin expression. J Oral Pathol Med 46: 267-275, 2017.

58. Kok-Sin T, Mokhtar NM, Ali Hassan NZ, Sagap I, Mohamed Rose I, Harun R and Jamal R: Identification of diagnostic markers in colorectal cancer via integrative epigenomics and genomics data. Oncol Rep 34: 22-32, 2015.

59. Yang X, Deng Y, He RQ, Li XJ, Ma J, Chen G and Hu XH: Upregulation of HOXA11 during the progression of lung adenocarcinoma detected via multiple approaches. Int J Mol Med 42: 2650-2664, 2018

60. Shang L, Ye X, Zhu G, Su H, Su Z, Chen B, Xiao K, Li L, Peng M and Peng T: Prognostic value of integrin variants and expression in post-operative patients with HBV-related hepatocellular carcinoma. Oncotarget 8: 76816-76831, 2017.

61. Haider S, Wang J, Nagano A, Desai A, Arumugam P, Dumartin L, Fitzgibbon J, Hagemann T, Marshall JF, Kocher HM, et al: A multi-gene signature predicts outcome in patients with pancreatic ductal adenocarcinoma. Genome Med 6: 105, 2014.

62. Yan P, He Y, Xie K, Kong S and Zhao W: In silico analyses for potential key genes associated with gastric cancer. PeerJ 6: e6092, 2018.

63. Zheng W, Jiang $\mathrm{C}$ and Li R: Integrin and gene network analysis reveals that ITGA5 and ITGB1 are prognostic in non-small-cell lung cancer. Onco Targets Ther 9: 2317-2327, 2016.

64. Mallawaaratchy DM, Buckland ME, McDonald KL, Li CC, Ly L, Sykes EK, Christopherson RI and Kaufman KL: Membrane proteome analysis of glioblastoma cell invasion. J Neuropathol Exp Neurol 74: 425-441, 2015.

65. Maschler S, Wirl G, Spring H, Bredow DV, Sordat I, Beug H and Reichmann E: Tumor cell invasiveness correlates with changes in integrin expression and localization. Oncogene 24: 2032-2041, 2005.

66. Yang $\mathrm{J}$ and Wang $\mathrm{N}$ : Analysis of the molecular mechanism of osteosarcoma using a bioinformatics approach. Oncol Lett 12: 3075-3080, 2016.

67. Fang ZQ, Zang WD, Chen R, Ye BW, Wang XW, Yi SH, Chen W, $\mathrm{He} \mathrm{F}$ and Ye G: Gene expression profile and enrichment pathways in different stages of bladder cancer. Genet Mol Res 12: 1479-1489, 2013.

This work is licensed under a Creative Commons Attribution-NonCommercial-NoDerivatives 4.0 International (CC BY-NC-ND 4.0) License. 